\title{
The interactive effects of ketamine and magnesium upon depressive-like pathology
}

This article was published in the following Dove Press journal:

Neuropsychiatric Disease and Treatment

8 September 2016

Number of times this article has been viewed

\section{Sara Razmjou \\ Darcy Litteljohn \\ Chris Rudyk \\ Shuaib Syed \\ Melanie Clarke \\ Rowan Pentz \\ Zach Dwyer \\ Shawn Hayley}

Department of Neuroscience, Carleton University, Ottawa,

Ontario, Canada
Correspondence: Shawn Hayley Department of Neuroscience, Carleton University, I I 25 Colonel By Drive,

Ottawa, Ontario, Canada KIS 5B6

$\mathrm{Tel}+\mathrm{l} 6135202600$ ext 6314

$\mathrm{Fax}+\mathrm{I} 6135204052$

Email shawn_hayley@carleton.ca
Abstract: Approximately one-third of patients with major depressive disorders (MDDs) are resistant to current treatment methods, and the majority of cases relapse at some point during therapy. This has resulted in novel treatments being adopted, including subanesthetic doses of ketamine, which affects aberrant neuroplastic circuits, glutamatergic signaling, and the production of brain-derived neurotrophic factor. Ketamine rapidly relieves depressive symptoms in treatment-resistant major depressive disorder patients with effects that last for up to 2 weeks even after a single administration. However, it is also a drug with an abusive potential and can have marked side effects. Hence, this study aimed at enhancing the antidepressant-like effects of ketamine (allowing for lower dosing regimens) by coadministering magnesium hydroaspartate $\left(\mathrm{Mg}^{2+}\right.$ normally affects the same receptors as ketamine) and also assessed whether an $\mathrm{Mg}^{2+}$-deficient diet would modify the impact of ketamine. It was found that a single $15 \mathrm{mg} / \mathrm{kg}$ dose of ketamine did indeed induce rapid antidepressant-like effects in the forced swim test but did not affect brain levels of the brain-derived neurotrophic factor. Contrary to our hypothesis, magnesium administration or deficiency did not influence the impact of ketamine on these outcomes. Thus, these data do not support the use of magnesium as an adjunct agent and instead suggest that further research involving other antidepressant and animal models is required to confirm the present findings.

Keywords: ketamine, depression, treatment resistance, ghrelin, BDNF, NMDA

\section{Introduction}

Major depressive disorder is a recurrent chronic psychiatric condition that affects over 121 million people worldwide annually. ${ }^{1}$ Unfortunately, the currently used antidepressants (even when used in combination) have several caveats, including a slow onset of action, requiring weeks or months of treatment to produce therapeutic effects., ${ }^{2,3}$ Moreover, recent estimates indicate that approximately $30 \%$ of depressed patients do not respond to these antidepressant therapies, and even in case of responders, residual symptoms are still often present and there is a very high risk of relapse. ${ }^{4-7}$

Exciting emerging evidence indicates that the noncompetitive N-methyl-D-aspartate (NMDA) glutamate receptor antagonist, ketamine, which is widely used for its anesthetic and analgesic properties, could be a useful treatment option for depression. ${ }^{8-10}$ When used at low doses, a single injection of ketamine was found to promote fast-acting (within hours) antidepressant and antisuicidal effects. ${ }^{8,11-13}$ Importantly, ketamine was rapidly effective in patients who were previously treatment-resistant. $3,11,14$

Ketamine rapidly (within hours) increases synaptogenesis, and thus, synaptic plasticity involved in learning and memory. ${ }^{15}$ Such synaptogenic changes would be expected to influence the cognitive processing of emotionally relevant stimuli. Indeed, brain-derived neurotrophic factor (BDNF) levels were reduced in major depressive 
disorder patients, ${ }^{16}$ and postmortem studies have reported reduced BDNF expression in hippocampus and prefrontal cortex (PFC) of depressed suicides. ${ }^{17,18}$ It has been reported that ketamine-mediated NMDA receptor blockade increased hippocampal BDNF levels and that this effect might contribute to its antidepressant effects. , $^{3,19,20}$

Despite its beneficial antidepressant effects, ketamine's psychotomimetic effects and abuse potential limit its widespread use. Likewise, high doses of ketamine and other NMDA receptors have been associated with neurotoxic effects in animal models. ${ }^{21} \mathrm{~A}$ better potential treatment strategy might involve the coadministration of agents that can synergize with ketamine in the promotion of an antidepressant response. This would allow for even lower doses and a less frequent ketamine-dosing regimen. In this regard, we posit that magnesium $\left(\mathrm{Mg}^{2+}\right)$ could be a potential cofactor that might augment the effects of ketamine. Indeed, $\mathrm{Mg}^{2+}$ is normally present as a channel blocker on the NMDA receptor, upon which ketamine exerts its antagonist actions. Moreover, there are reports indicating that $\mathrm{Mg}^{2+}$ is involved in the pathophysiology of mood disorders ${ }^{22-24}$ and that administration of the $\mathrm{Mg}^{2+}$ organic salt, magnesium hydroaspartate, created antidepressant-like effects. ${ }^{25,26}$ In fact, elevated intracerebral $\mathrm{Mg}^{2+}$ levels were reported with several existing antidepressant agents. ${ }^{27,28}$

In this study, the potential additive or synergistic antidepressant-like actions of ketamine plus magnesium treatment were explored. In order to ascertain whether any interactive effects of ketamine and magnesium might be related to trophic brain changes, BDNF levels within the hippocampus and PFC were assessed.

\section{Materials and methods Animals}

Male mice (CD1, 6-8 weeks of age) were acclimatized to the vivarium for a period of 1 week before experimental procedures began. Animals were singly housed in standard polypropylene cages $(27 \times 21 \times 14 \mathrm{~cm})$, and a 12 -hour light/ dark cycle (light phase: 8:00 to 20:00 hours) was maintained. Water and Teklad Global mouse chow were provided ad libitum, and the room temperature was maintained at $21^{\circ} \mathrm{C}$. All the procedures were approved by the Carleton University Animal Care Committee and adhered to the guidelines of the Canadian Council for the care of animals in research.

\section{Treatment procedures}

This experiment examined the effects of chronic administration of magnesium hydroaspartate prior to a single ketamine injection. Thirty-two mice were randomly divided into two groups. ( $\mathrm{n}=16$ per group): 1) saline and 2) magnesium hydroaspartate. The treatments were administered intraperitoneally once daily for 14 days. Then each group of mice was subdivided into two groups ( $\mathrm{n}=8$ per group); one receiving ketamine $(15 \mathrm{mg} / \mathrm{kg})$ and the other saline on the test day. Injection side was randomized, and sterile procedures were used to reduce the chances of any infection/inflammation.

\section{Behavioral procedure}

On the test day, which was 24 hours after the last magnesium injection, mice were injected either with ketamine or with saline. One hour later, animals were subjected to the forced swim test (FST). The FST was performed based on the methods suggested by Liu et al. ${ }^{15}$ Mice were placed in a 2,500-mL beaker filled two-thirds with $22^{\circ} \mathrm{C} \pm 1{ }^{\circ} \mathrm{C}$ water. They were allowed to swim for 6 minutes during which time their activity was videotaped. Immobility was defined as the absence of active, escape-oriented behaviors such as swimming, jumping, rearing, and sniffing and was assessed during the last 240 seconds of the test. The recorded videos were later scored by a person blind to the treatment groups.

In order to assess whether the drug treatments might be affecting the motor activity (which could confound FST results), the open field test was used, as described by Beurel et al. ${ }^{29}$ A $50 \mathrm{~cm}^{3}$ open, black Plexiglas arena floor was divided into 36 squares $(8 \times 8 \mathrm{~cm})$; then each animal was randomly placed in one of the four corners, and their locomotor activity was recorded for a period of 10 minutes. The number of lines crossed by each mouse was counted by a person blind to the study. The open field test was also used to assess anxiety-like behaviors in mice, as previously described by Litteljohn et al. ${ }^{30}$ The open, black Plexiglas arena was divided into predefined zones (outer, middle, and inner/ center). The amount of time spent in each zone was measured by a person blind to the study groups. Decreased time spent in the center zone is an index of anxiety-like behavior. The arena was cleaned with $10 \% \mathrm{EtOH}$ between trials.

Immediately after testing, all the animals were rapidly decapitated and brains collected. The hippocampus and PFC were carefully microdissected from $0.5 \mathrm{~mm}$ coronal tissue slices. All the tissues were placed on dry ice followed by storage at $-80^{\circ} \mathrm{C}$ until assayed.

\section{BDNF analyses}

Prior to analysis, samples were removed from the freezer and weighed. Lysis buffer (100 mM PIPES [pH 7], $500 \mathrm{mM}$ $\mathrm{NaCl}, 0.2 \%$ Triton X-100, 0.1\% $\mathrm{NaN}_{3}, 2 \% \mathrm{BSA}, 2 \mathrm{mM}$ EDTA $\left.\cdot \mathrm{Na}_{2} \cdot 2 \mathrm{H}_{2} \mathrm{O}\right), 200 \mu \mathrm{M}$ Phenylmethylsulfonyl fluoride (frozen in isopropanol), $10 \mu \mathrm{M}$ leupeptin (frozen separately in deionized water), and $0.3 \mu \mathrm{M}$ pepstatin (frozen separately in 
dimethyl sulfoxide) were then pipetted into each tube containing hippocampal or PFC samples ( $2 \mathrm{~mL})$. Samples were then homogenized and sonicated (Virtis Virsonic; Virtis Company, Gardiner, NY; with a microtip at power level 4 and pulses at 1-second intervals for 15 seconds). Then an additional $2 \mathrm{~mL}$ of lysis buffer was added to the samples, and they were again sonicated. Samples were split and one half of each sample was spiked (artificially increasing the concentration of BDNF by $250 \mathrm{pg} / \mathrm{mL}$ to determine percent recovery). Samples were centrifuged for 30 minutes at $16,000 \times g$ at $4^{\circ} \mathrm{C}$. Supernatants were removed and frozen at $-80^{\circ} \mathrm{C}$ until analysis.

BDNF expression was determined by Western blot analysis. Protein concentration in the supernatants of tissue extracts was determined using a bicinchoninic acid protein assay kit (Pierce Biotechnology, Inc., Rockford, IL, USA). A quantity of 30-50 $\mu \mathrm{g}$ of total proteins was loaded onto a $4 \%-15 \%$ gradient polyacrylamide gel, electrophoretically transferred to polyvinylidene difluoride membrane and probed with the following primary antibody: $\operatorname{BDNF}(1: 1,000$; Santa Cruz Biotechnology, Inc., Dallas, TX, USA). $\beta$-Actin (1:2,000; Sigma-Aldrich Co., St Louis, MO, USA) was used as an internal control. Secondary antibodies were horseradish peroxidase conjugated to antimouse IgG (Sigma-Aldrich Co.). The membrane was developed using an enhanced chemiluminescence detection system (Pierce Biotechnology, Inc.). Densitometric analysis was performed using the quantification of immunoblotting using the Scion Image Software (Scion Corporation).

\section{Statistical analyses}

Statistical analyses were performed using SPSS (IBM Corporation, Armonk, NY, USA). Differences among experimental groups in the FST and in the assessment of BDNF levels will be determined by analysis of variance. Independent $t$-test was used when two groups were compared. Where there was an interaction effect, two-way analyses of variance were then followed by Fisher's planned comparisons $(P<0.05)$. Data are presented in the form of mean \pm standard error of the mean. All data were analyzed using the statistical software SPSS (Version 19.0), and the differences were considered statistically significant when $P<0.05$.

\section{Results}

\section{Forced swim test}

As shown in Figure 1, mice treated with ketamine $(15 \mathrm{mg} / \mathrm{kg})$ spent significantly less time immobile than their saline-injected counterparts $\left(F_{(1,30)}=5.2, P=0.031\right)$. However, forced swim immobility was neither affected by the magnesium treatment $\left(F_{(1,30)}=0.686, P=0.415\right)$ nor was there any indication of an

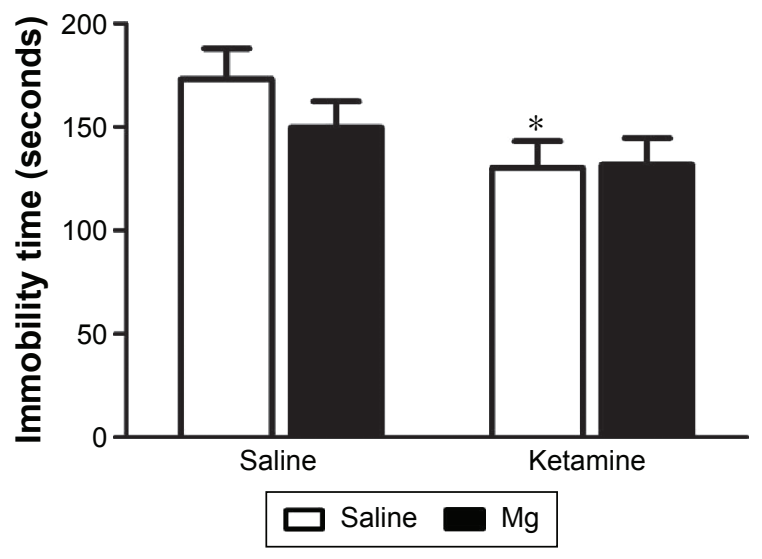

Figure I Immobility in the forced swim test.

Notes: Effect of ketamine and magnesium treatment on immobility time in the forced swim test. Mice treated with ketamine $(15 \mathrm{mg} / \mathrm{kg})$ spent significantly less time immobile than the saline group $(* P<0.05)$. No significant effect of ketamine and magnesium treatment on immobility time. A significant main effect for ketamine was obtained by ANOVA. All data are expressed as mean \pm standard error of the mean.

interaction between ketamine and magnesium $\left(F_{(1,30)}=0.873\right.$, $P=0.359)$.

Locomotor activity in the open field test

As shown in Figure 2, the overall locomotion activity was not influenced by ketamine or magnesium treatment $\left(F_{(1,32)}=0.886, P=0.358\right)$, indicating that the treatments were not having general deleterious consequences on motor behavior.

\section{Anxiety-like behavior in the open field test}

In the open filed arena, no significant difference was found between the time spent in the center zone $\left(F_{(1,32)}=0.143\right.$, $P=0.708)$, middle zone $\left(F_{(1,32)}=0.148, P=0.734\right)$, or outer zone $\left(F_{(1,32)}=0.066, P=0.798\right.$; Figure 3$)$. Importantly, reduced

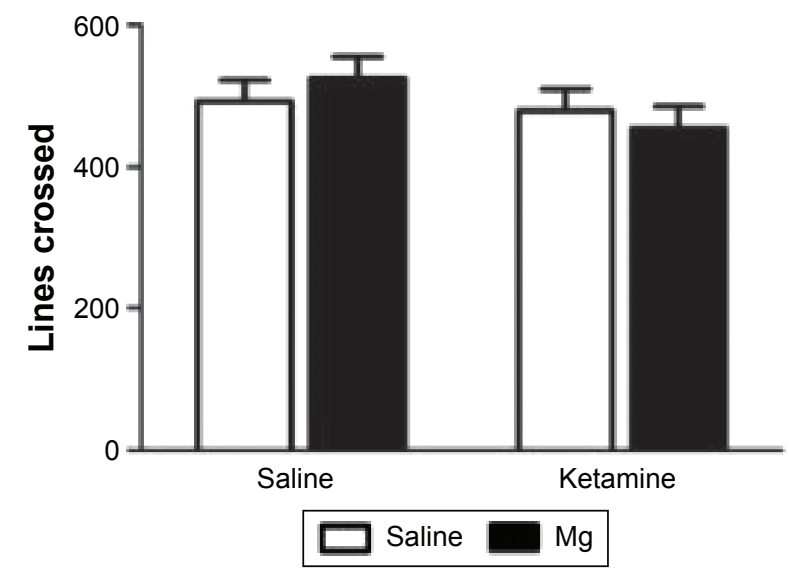

Figure $\mathbf{2}$ Locomotor activity in the open field test.

Notes: Locomotor activity was expressed as the total number of lines passed by mice over 10 minutes in a $50 \mathrm{~cm}^{3}$ open white Plexiglas arena, which was divided into 36 squares, each $10 \mathrm{~cm}$. No significant difference among groups was observed. All data are expressed as mean \pm standard error of the mean. 

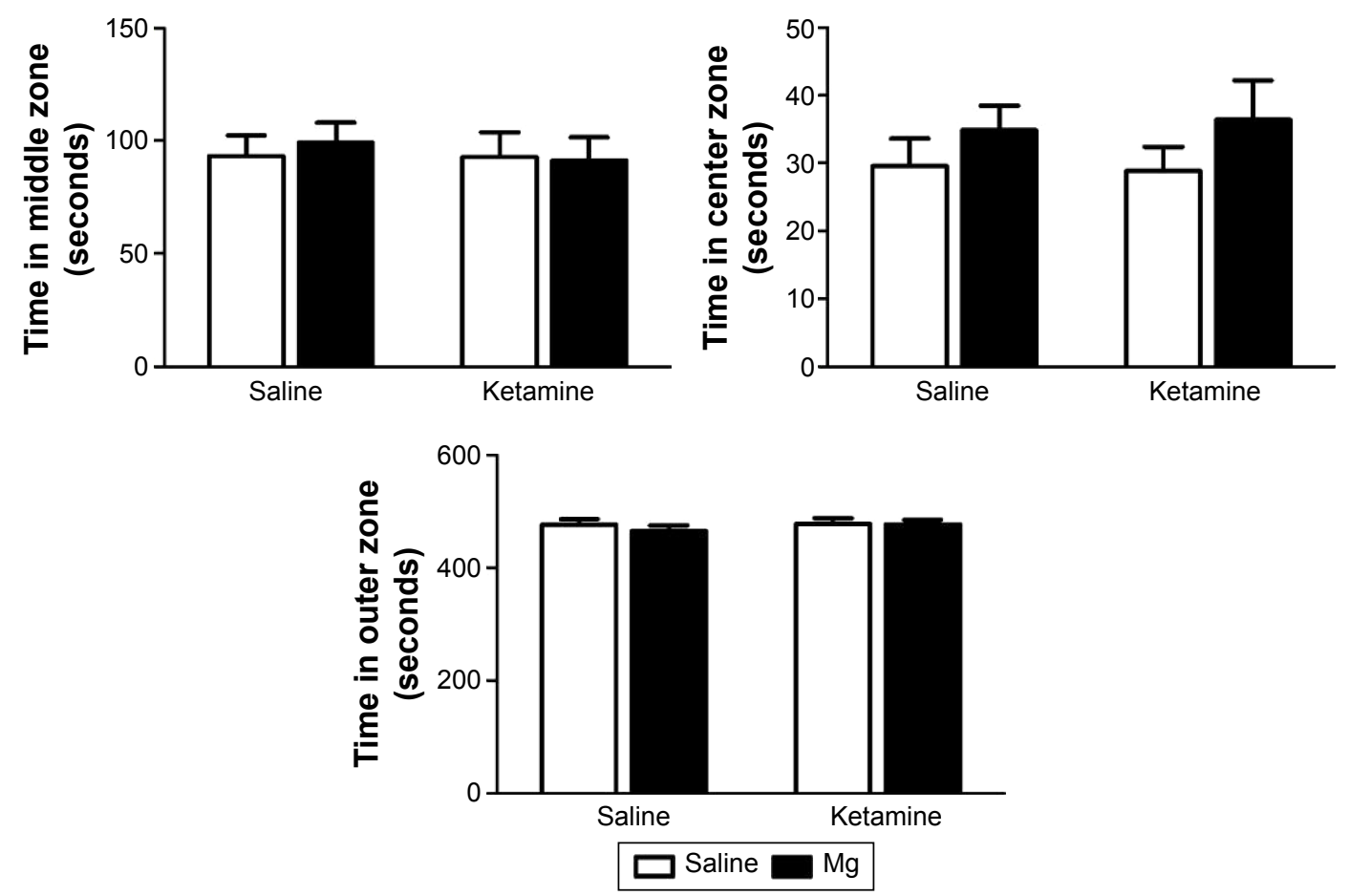

Figure 3 Anxiety-like behavior in the open field test.

Notes: Effect of ketamine and magnesium treatment on anxiety-like behavior in the open field test. Time spent in the center zone ( $P=0.708)$, middle zone ( $P=0.734)$, and outer zone were measured in seconds. No significant difference was found in any of the groups. All data are expressed as mean \pm standard error of the mean.

exploration of the central portion of this arena is typically taken as an index of anxiety-like behavior.

\section{PFC and hippocampal BDNF expression}

Western blot analysis of hippocampal BDNF protein levels revealed no significant ketamine $\times$ magnesium treatment interaction $\left(F_{(1,32)}=0.08, P=0.90\right)$. The main effects of either magnesium $\left(F_{(1,32)}=1.43, P=0.241\right)$ or ketamine $\left(F_{(1,32)}=0.186\right.$, $P=0.669$; Figure 4) were also not revealed. Similarly, PFC
BDNF protein levels did not vary by ketamine $\times$ magnesium treatment interaction $\left(F_{(1,32)}=1.244, P=0.356\right)$, and the main effects of magnesium $\left(F_{(1,32)}=0.916, P=0.347\right)$ or ketamine $\left(F_{(1,32)}=1.46, P=0.236\right)$ were not significant.

\section{Discussion}

Current pharmacotherapies for major depression include selective serotonin and noradrenaline reuptake inhibitors, which have a long delay of action and actually fail to work
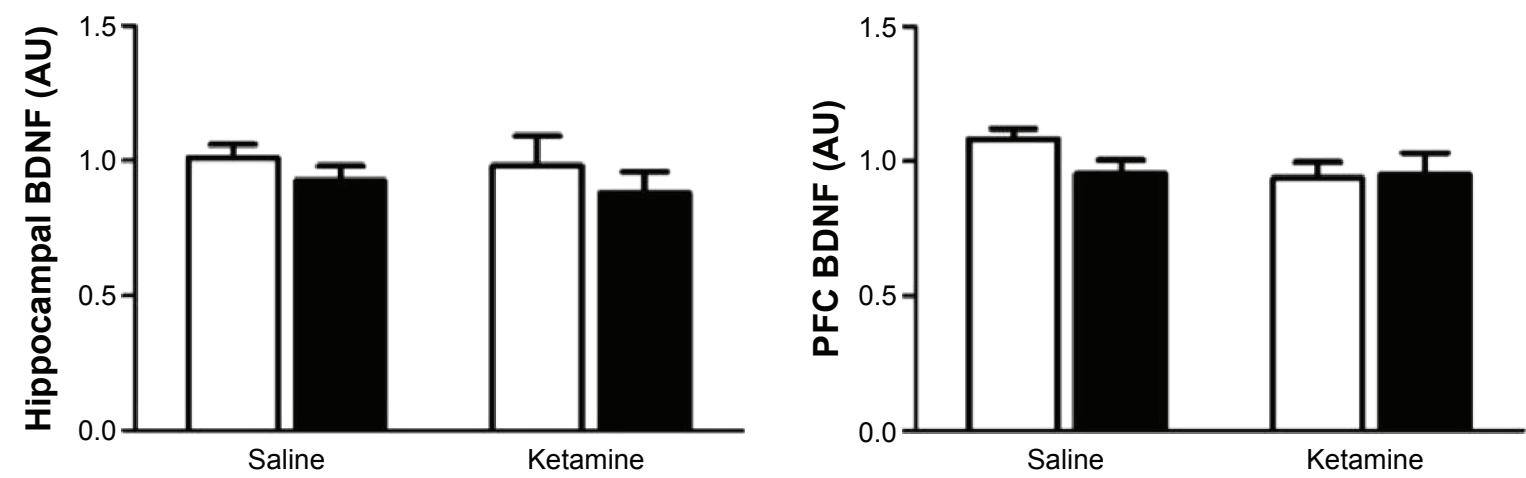

\section{Saline $\mathrm{Mg}$}

Figure 4 Results of BDNF Western blot.

Notes: Prefrontal cortex BDNF on the right side and hippocampal BDNF on the left side. No significant difference was found among groups either for PFC BDNF or hippocampal BDNF.

Abbreviations: BDNF, brain-derived neurotrophic factor; PFC, prefrontal cortex. 
in many patients. ${ }^{7}$ Therefore, there is an urgent need for the development of faster-acting antidepressants, as well as novel nonmonoaminergic agents to benefit a large number of treatment-resistant patients. In this regard, a lot of recent works have been devoted to examining the antidepressant efficacy of compounds targeting the glutamatergic pathway. This research has been spurred on by the finding that the ionotropic glutamate N-methyl-D-aspartate receptor is involved in the etiology of major depression. ${ }^{8,9,19}$ Since then, numerous clinical and infrahuman studies have reported that NMDA receptor antagonists, most notably ketamine, can promote rapid antidepressant-like behavioral consequences. ${ }^{15,19,29,31-33}$ In fact, a recent meta-analysis of several clinical studies also suggests the effectiveness of single administration of ketamine in rapid treatment of major depressive episodes. ${ }^{34}$

Despite the mounting evidence of ketamine's antidepressant potential, and notwithstanding some important recent advances in our understanding of various molecular and cellular sequelae following low-dose ketamine treatment, the precise mechanisms underlying ketamine's antidepressant effects are still largely unknown. It has been suggested that the antidepressant effect of ketamine may be due to an increased expression of BDNF, which, in turn, induces synaptic plasticity. ${ }^{19,35}$ Indeed, NMDA receptors interact with BDNF/Trk B pathway to promote synaptic plasticity. Conversely, blockade of NMDA receptor by ketamine deactivated eukaryotic elongation factor 2 kinase, which leads to reduced eukaryotic elongation factor 2 phosphorylation and consequent desuppression of BDNF translation., ${ }^{2,20}$ It also bears mentioning that a recent study ${ }^{36}$ highlights the role of early and sustained activation of $\alpha$-amino-3hydroxy-5-methyl-4-isoxazole propionic acid receptors in ketamine's antidepressant responses rather than NMDA receptor inhibition.

While there remains much to be discovered about how ketamine promotes antidepressant outcomes, it is important to keep in mind that a major impetus of this line of inquiry has been the considerable concern over the drug's potential adverse effects (tolerance, abuse, side effects)., ${ }^{2,19,37}$ Indeed, the hope is that a better understanding of the molecular and cellular pathways subserving ketamine's antidepressant action will lead to the development of novel glutamatergic drugs that share with ketamine its mode of action/ antidepressant potential but not its unwanted effects. ${ }^{38}$ In the meantime, further studies are needed to find the minimum effective and safe dose of ketamine or to find a favorable ketamine combination therapy that could permit the downtitrating of drug doses.
Poleszak et $\mathrm{al}^{39}$ demonstrated the antidepressant-like effect of magnesium in conjunction with NMDA antagonists (CGP 37849, MK-801, L-701,324) in mice; importantly, these authors suggested that administration of magnesium could be an effective method to reduce the NMDA antagonist dose. Magnesium as an iatrogenic NMDA receptor antagonist has a proven antidepressant-like activity in the FST. ${ }^{25,26}$ Furthermore, it has been used as a supplementary therapy for mood disorders, reducing significantly the use of lithium, benzodiazepines, and neuroleptics in joint therapy. ${ }^{40}$

The present study evaluated the effect of ketamine, delivered either as monotherapy or in combination with magnesium on hippocampal and PFC BDNF expression and behavioral performance. Locomotor activity and anxiety-like behavior in an open field were unaffected by ketamine or magnesium treatment. Similarly, previous studies demonstrated that neither ketamine nor magnesium has any effect on locomotor activity in mice..$^{22-24,41-43}$ However, as expected, we found that ketamine reduced immobility in a FST, and this indicated that the drug had antidepressant-like effects that were unrelated to any anxiety or locomotor parameters.

Magnesium-deficient diets were reported to induce anxiety-related behavior in mice, ${ }^{44}$ and there are studies indicating an anxiolytic-like activity of magnesium in mice. ${ }^{22-24}$ This, however, contradicts the results of our present study. Furthermore, animal data regarding the impact of ketamine on anxiety behaviors are contradictory: in a study conducted by Silvestre et al, ${ }^{45}$ ketamine was found to produce anxiogenic-like effects in rats, but in another study, the drug was shown to promote anxiolytic responses (in the elevated plus maze) ${ }^{46}$ Similarly, the evidence for an anxiolytic-like effect of ketamine in humans is equivocal and is probably subject to complex dose-and-time effects. For instance, in a study of healthy human volunteers, the participants reported a decrease in anxiety after a low dose of ketamine $(0.1 \mathrm{mg} / \mathrm{kg}$ intravenously), but an increase in anxiety at a higher dose $\left(0.5 \mathrm{mg} / \mathrm{kg}\right.$ intravenously) ${ }^{47}$ Ketamine is often used as a preoperative agent for painful medical procedures for both adults and children, presumably due to its dissociative anesthetic and anxiolytic properties. ${ }^{48,49}$ However, the potential antianxiety effects of ketamine may be secondary to sedation and analgesia, ${ }^{50}$ which is particularly evident with doses higher than the subanesthetic ones that are used in this study (usually substantially $>30 \mathrm{mg} / \mathrm{kg}$ ).

Pochwat et a ${ }^{51}$ evaluated the effect of three different doses of magnesium $(10,15$, and $20 \mathrm{mg} / \mathrm{kg})$ in the chronic mild stress model of depression in rats. They observed an antidepressantlike effect of magnesium at a dose of $15 \mathrm{mg} / \mathrm{kg}$ in the sucrose 
preference test, beginning from the third week of treatment. Moreover, the antidepressant-like behavioral effect of magnesium coincided with reduced brain regional (hippocampus, PFC, and amygdala) expression of proteins related to glutamatergic signaling (including GluN1, GluN2A, and PSD-95).

The underlying mechanism(s) of the rapid antidepressant effect of ketamine is/are not known. However, it has been suggested that the fast-acting behavioral antidepressantlike effect of ketamine is related to the rapid upregulation of BDNF and the consequent potentiation of synaptic plasticity. ${ }^{20}$ Indeed, acute administration of ketamine was shown to induce increased hippocampal and PFC BDNF levels, which coincided with improved behavioral responses in rodents. ${ }^{19,52,53}$ Yet, we presently failed to detect any effect of ketamine on hippocampal or PFC BDNF levels. This might be due to the fact that we did not use mice with depression-like phenotype in our study, as ketamine was shown to improve decreased BDNF expression in inflammation-induced depressed mice ${ }^{54}$ and learned helplessness rats. ${ }^{55,56}$ Indeed, Zhang et $\mathrm{al}^{57}$ found that 8 days after a single injection, ketamine did reverse the stressor-induced reduction of BDNF in the PFC and hippocampus on Day 20 of a daily social defeat stressor paradigm. However, Garcia et $\mathrm{al}^{58}$ failed to detect any change in hippocampal BDNF levels after chronic mild unpredictable stress as well. The reason for the discrepancies between the studies is not immediately apparent but could certainly have to do with the obvious stress/testing procedural differences, as well as species/strain differences. In particular, the Garcia et $\mathrm{al}^{58}$ study used rats, whereas Zhang et $\mathrm{al}^{57}$ used C57BL/6 mice, and we used CD1 mice in our study.

Also, we did not detect any effect of magnesium on hippocampal or PFC BDNF levels. This is in contrast to a study ${ }^{59}$ that found that magnesium is, in fact, capable of increasing BDNF expression and various markers of synaptic plasticity. One of the possible reasons we did not see an effect of magnesium might be the subtherapeutic duration of magnesium administration in our experiment. Indeed, Pochwat et $\mathrm{al}^{51}$ found changes in the level of proteins related to glutamatergic system in PFC, hippocampus, and amygdala after 3 weeks of magnesium treatment. We chose a 2-week period based on the Poleszak et $\mathrm{al}^{23}$ study in which they found a reduced immobility time in FST after 2 weeks of magnesium administration. Also, an in vitro study conducted by Slutsky et $\mathrm{al}^{60}$ suggested that synaptic plasticity is sensitive only to magnesium levels in the physiological range. Therefore, maintaining magnesium at proper physiological concentrations should be taken into consideration.
In summary, the results of this study do not support the utility of magnesium as an adjunct treatment with ketamine for depression. Our data also suggest that although ketamine has robust antidepressant-like effects, its effectiveness as an anxiolytic was not obvious in our open field paradigm. Finally, lack of brain BDNF changes induced by ketamine and magnesium treatment might speak to the sensitivity of our procedures but more likely is related to timing. Specifically, it is expected that BDNF changes would have occurred early following ketamine administration; but it is perhaps not surprising that these effects were not prolonged for the 3-week period of our study. Thus, ketamine did not sensitize or have enduring effects upon the ability of chronic magnesium treatment to influence BDNF. Similarly, the magnesium dose alone was clearly not sufficient to trigger BDNF alterations. Thus, further studies are clearly needed to ascertain whether magnesium really has any potential as an adjunctive agent with ketamine or even other more traditional antidepressants, such as fluoxetine or citalopram.

\section{Acknowledgments}

This paper includes work based on the master thesis submitted by coauthor Sara Razmjou to Carleton University: https://curve.carleton.ca/cc1977e4-6b95-4ad3-84c4$\underline{42 \mathrm{~cd} 6 \mathrm{c} 0 \mathrm{cb} 5 \mathrm{a} 5}$.

\section{Disclosure}

The authors report no conflicts of interest in this work.

\section{References}

1. Tizabi Y, Bhatti BH, Manaye FK, Das RJ, Akinfiresoye L. Antidepressantlike effects of low ketamine dose is associated with increased hippocampal AMPA/NMDA receptor density ratio in female Wistar-Kyoto rats. Neuroscience. 2012;213:72-80.

2. Kavalali ET, Monteggia LM. Synaptic mechanisms underlying rapid antidepressant action of ketamine. Am J Psychiatry. 2012;169(11): $1150-1156$.

3. Machado-Vieira R, Yuan P, Brutsche N, et al. Brain-derived neurotrophic factor and initial antidepressant response to an N-methyl-D-aspartate antagonist. J Clin Psychiatry. 2009;70(12):1662-1666.

4. Pacher P, Kohegyi E, Kecskemeti V, Furst S. Current trends in the development of new antidepressants. Curr Med Chem. 2001;8(2):89-100.

5. Ghaemi SN. Why antidepressants are not antidepressants: STEP-BD, $\mathrm{STAR}^{*} \mathrm{D}$, and the return of neurotic depression. Bipolar Disord. 2008; 10(8):957-968.

6. Gerden JF. The burden of disease for treatment-resistant depression. J Clin Psychiatry. 2001;62(Suppl 16):26-31.

7. Trivedi MH, Rush AJ, Wisniewski SR, et al; STAR*D Study Team. Evaluation of outcomes with citalopram for depression using measurement-based care in STAR*D: implications for clinical practice. Am J Psychiatry. 2006;163(1):28-40.

8. Zarate CA Jr, Singh JB, Carlson PJ, et al. A randomized trial of an $\mathrm{N}$-methyl-D-aspartate antagonist in treatment-resistant major depression. Arch Gen Psychiatry. 2006;63(8):856-864. 
9. Berman RM, Cappiello A, Anand A, et al. Antidepressant effects of ketamine in depressed patients. Biol Psychiatry. 2000;47(4): 351-314.

10. Larkin GL, Beautrais AL. A preliminary naturalistic study of low-dose ketamine for depression and suicide ideation in the emergency department. Int J Neuropsychopharmacol. 2011;14(8):1127-1131.

11. Liebrenz M, Borgeat A, Leisinger R, Stohler R. Intravenous ketamine therapy in a patient with a treatment-resistant major depression. Swiss Med Wkly. 2007;137(15-16):234-236.

12. Price RB, Nock MK, Charney DS, Mathew SJ. Effects of intravenous ketamine on explicit and implicit measures of suicidality in treatmentresistant depression. Biol Psychiatry. 2009;66(5):522-526.

13. Ibrahim L, Diazgranados N, Franco-Chaves J, et al. Course of improvement in depressive symptoms to a single intravenous infusion of ketamine vs add-on riluzole: results from a 4-week, double-blind, placebo-controlled study. Neuropsychopharmacology. 2012;37(6):1526-1533.

14. Mathew SJ, Price RB, Shungu DC, et al. A pilot study of the effects of chronic paroxetine administration on hippocampal N-acetylaspartate in generalized anxiety disorder. J Psychopharmacol. 2010;24(8):1175-1181.

15. Liu RJ, Lee FS, Li XY, Bambico F, Duman RS, Aghajanian GK. Brain-derived neurotrophic factor Val66Met allele impairs basal and ketamine-stimulated synaptogenesis in prefrontal cortex. Biol Psychiatry. 2012;71(11):996-1005.

16. Yoshimura R, Kishi T, Hori H, et al. No association between the response to the addition of an atypical antipsychotic drug to an SSRI or SNRI and the BDNF (Val66Met) polymorphism in refractory major depressive disorder in japanese patients. Clin Psychopharmacol Neurosci. 2012;10(1):49-53.

17. Krishnan V, Han MH, Graham DL, et al. Molecular adaptations underlying susceptibility and resistance to social defeat in brain reward regions. Cell. 2007;131(2):391-404.

18. Yu H, Chen ZY. The role of BDNF in depression on the basis of its location in the neural circuitry. Acta Pharmacol Sin. 2011;32(1):3-11.

19. Garcia LS, Comim CM, Valvassori SS, et al. Acute administration of ketamine induces antidepressant-like effects in the forced swimming test and increases BDNF levels in the rat hippocampus. Prog Neuropsychopharmacol Biol Psychiatry. 2008;32(1):140-144.

20. Autry AE, Adachi M, Nosyreva E, et al. NMDA receptor blockade at rest triggers rapid behavioural antidepressant responses. Nature. 2011;475(7354):91-95.

21. Olney JW, Labruyere J, Wang G, Wozniak DF, Price MT, Sesma MA. NMDA antagonist neurotoxicity: mechanism and prevention. Science. 1991;254(5037):1515-1518.

22. Poleszak E, Wlaź P, Szewczyk B, et al. Enhancement of antidepressantlike activity by joint administration of imipramine and magnesium in the forced swim test: behavioral and pharmacokinetic studies in mice Pharmacol Biochem Behav. 2005;81(3):524-529.

23. Poleszak E, Wlaź P, Kedzierska E, et al. Effects of acute and chronic treatment with magnesium in the forced swim test in rats. Pharmacol Rep. 2005;57(5):654-658.

24. Poleszak E, Wlaź P, Wróbel A, Fidecka S, Nowak G. NMDA/glutamate mechanism of magnesium-induced anxiolytic-like behavior in mice. Pharmacol Rep. 2008;60(5):655-663.

25. Poleszak E, Szewczyk B, Kedzierska E, Wlaź P, Pilc A, Nowak G. Antidepressant- and anxiolytic-like activity of magnesium in mice. Pharmacol Biochem Behav. 2004;78(1):7-12.

26. Decollogne S, Tomas A, Lecerf C, Adamowicz E, Seman M. NMDA receptor complex blockade by oral administration of magnesium: comparison with MK-801. Pharmacol Biochem Behav. 1997;58(1): 261-268.

27. Iosifescu DV, Bolo NR, Nierenberg AA, Jensen JE, Fava M, Renshaw PF. Brain bioenergetics and response to triiodothyronine augmentation in major depressive disorder. Biol Psychiatry. 2008;63(12): 1127-1134.
28. Abukhdeir AM, Layden BT, Minadeo N, Bryant FB, Stubbs EB Jr, Mota de Freitas D. Effect of chronic Li+ treatment on free intracellular Mg2+ in human neuroblastoma SH-SY5Y cells. Bipolar Disord. 2003;5(1):6-13.

29. Beurel E, Song L, Jope RS. Inhibition of glycogen synthase kinase-3 is necessary for the rapid antidepressant effect of ketamine in mice. $\mathrm{Mol}$ Psychiatry. 2011;16(11):1068-1070.

30. Litteljohn D, Cummings A, Brennan A, et al. Interferon-gamma deficiency modifies the effects of a chronic stressor in mice: Implications for psychological pathology. Brain Behav Immun. 2010;24(3): 462-473.

31. Li N, Lee B, Liu RJ, et al. mTOR-dependent synapse formation underlies the rapid antidepressant effects of NMDA antagonists. Science. 2010;329(5994):959-964.

32. Réus GZ, Stringari RB, Ribeiro KF, et al. Ketamine plus imipramine treatment induces antidepressant-like behavior and increases CREB and BDNF protein levels and PKA and PKC phosphorylation in rat brain. Behav Brain Res. 2011;221(1):166-171.

33. Pozzi L, Pollak Dorocic I, Wang X, Carlén M, Meletis K. Mice lacking NMDA receptors in parvalbumin neurons display normal depressionrelated behavior and response to antidepressant action of NMDAR antagonists. PLoS One. 2014;9(1):e83879.

34. McGirr A, Berlim MT, Bond DJ, Fleck MP, Yatham LN, Lam RW. A systematic review and meta-analysis of randomized, double-blind, placebo-controlled trials of ketamine in the rapid treatment of major depressive episodes. Psychol Med. 2015;45(4):693-704.

35. Castrén E, Võikar V, Rantamäki T. Role of neurotrophic factors in depression. Curr Opin Pharmacol. 2007;7(1):18-21.

36. Zanos P, Moaddel R, Morris PJ, et al. NMDAR inhibition-independent antidepressant actions of ketamine metabolites. Nature. 2016;533(7604): 481-486.

37. Browne CA, Lucki I. Antidepressant effects of ketamine: mechanisms underlying fast-acting novel antidepressants. Front Pharmacol. 2013;4:161.

38. Martinowich K, Jimenez DV, Zarate CA Jr, Manji HK. Rapid antidepressant effects: moving right along. Mol Psychiatry. 2013;18(8): 856-863.

39. Poleszak E, Wlaź P, Kedzierska E, et al. NMDA/glutamate mechanism of antidepressant-like action of magnesium in forced swim test in mice. Pharmacol Biochem Behav. 2007;88(2):158-164.

40. Heiden A, Frey R, Presslich O, Blasbichler T, Smetana R, Kasper S. Treatment of severe mania with intravenous magnesium sulphate as a supplementary therapy. Psychiatry Res. 1999;89(3):239-246.

41. Koike H, Iijima M, Chaki S. Involvement of AMPA receptor in both the rapid and sustained antidepressant-like effects of ketamine in animal models of depression. Behav Brain Res. 2011;224(1):107-111.

42. Ghasemi M, Raza M, Dehpour AR. NMDA receptor antagonists augment antidepressant-like effects of lithium in the mouse forced swimming test. J Psychopharmacol. 2010;24(4):585-594.

43. Engin E, Treit D, Dickson CT. Anxiolytic- and antidepressant-like properties of ketamine in behavioral and neurophysiological animal models. Neuroscience. 2009;161(2):359-369.

44. Singewald N, Sinner C, Hetzenauer A, Sartori SB, Murck H. Magnesium-deficient diet alters depression- and anxiety-related behavior in mice - influence of desipramine and Hypericum perforatum extract. Neuropharmacology. 2004;47(8):1189-1197.

45. Silvestre JS, Nadal R, Pallarés M, Ferré N. Acute effects of ketamine in the holeboard, the elevated-plus maze, and the social interaction test in Wistar rats. Depress Anxiety. 1997;5(1):29-33.

46. Hayase T, Yamamoto Y, Yamamoto K. Behavioral effects of ketamine and toxic interactions with psychostimulants. BMC Neurosci. 2006;7:25

47. Krystal JH, Karper LP, Seibyl JP, et al. Subanesthetic effects of the noncompetitive NMDA antagonist, ketamine, in humans. Psychotomimetic, perceptual, cognitive, and neuroendocrine responses. Arch Gen Psychiatry. 1994;51(3):199-214. 
48. Oda A, Iida H, Dohi S. Patient anxiety scores after low-dose ketamine or fentanyl for epidural catheter placement. Can J Anaesth. 2000;47(9): 910-913.

49. Karapinar B, Yilmaz D, Demirağ K, Kantar M. Sedation with intravenous ketamine and midazolam for painful procedures in children. Pediatr Int. 2006;48(2):146-151.

50. Ghai B, Grandhe RP, Kumar A, Chari P. Comparative evaluation of midazolam and ketamine with midazolam alone as oral premedication. Paediatr Anaesth. 2005;15(7):554-559.

51. Pochwat B, Szewczyk B, Sowa-Kucma M, et al. Antidepressant-like activity of magnesium in the chronic mild stress model in rats: alterations in the NMDA receptor subunits. Int J Neuropsychopharmacol. 2014; 17(3):393-405.

52. Zhou W, Wang N, Yang C, Li XM, Zhou ZQ, Yang JJ. Ketamineinduced antidepressant effects are associated with AMPA receptorsmediated upregulation of $\mathrm{mTOR}$ and BDNF in rat hippocampus and prefrontal cortex. Eur Psychiatry. 2014;29(7):419-423.

53. Yang C, Hu YM, Zhou ZQ, Zhang GF, Yang JJ. Acute administration of ketamine in rats increases hippocampal BDNF and mTOR levels during forced swimming test. Ups J Med Sci. 2013;118(1):3-8.

54. Zhang JC, Wu J, Fujita Y, et al. Antidepressant effects of TrkB ligands on depression-like behavior and dendritic changes in mice after inflammation. Int J Neuropsychopharmacol. 2014;18(4).
55. Yang C, Shirayama Y, Zhang JC, Ren Q, Hashimoto K. Regional differences in brain-derived neurotrophic factor levels and dendritic spine density confer resilience to inescapable stress. Int J Neuropsychopharmacol. 2015;18(7):pyu121.

56. Shirayama Y, Yang C, Zhang JC, Ren Q, Yao W, Hashimoto K. Alteration in brain-derived neurotrophic factor (BDNF) and its precursor proBDNF in the brain regions of a learned helplessness rat model and the antidepressant effects of a TrkB agonist and antagonist. Eur Neuropsychopharmacol. 2015;25(12):2449-2458.

57. Zhang JC, Yao W, Dong C, et al. Comparison of ketamine, 7,8dihydroxyflavone, and ANA-12 antidepressant effects in the social defeat stress model of depression. Psychopharmacology. 2015;232(23): 4325-4335.

58. Garcia LS, Comim CM, Valvassori SS, et al. Ketamine treatment reverses behavioral and physiological alterations induced by chronic mild stress in rats. Prog Neuropsychopharmacol Biol Psychiatry. 2009; 33(3):450-455.

59. Slutsky I, Abumaria N, Wu LJ, et al. Enhancement of learning and memory by elevating brain magnesium. Neuron. 2010;65(2):165-177.

60. Slutsky I, Sadeghpour S, Li B, Liu G. Enhancement of synaptic plasticity through chronically reduced $\mathrm{Ca}$ flux during uncorrelated activity. Neuron. 2004;44(5):835-849.
Neuropsychiatric Disease and Treatment

\section{Publish your work in this journal}

Neuropsychiatric Disease and Treatment is an international, peerreviewed journal of clinical therapeutics and pharmacology focusing on concise rapid reporting of clinical or pre-clinical studies on a range of neuropsychiatric and neurological disorders. This journal is indexed on PubMed Central, the 'PsycINFO' database and CAS,

\section{Dovepress}

and is the official journal of The International Neuropsychiatric Association (INA). The manuscript management system is completely online and includes a very quick and fair peer-review system, which is all easy to use. Visit http://www.dovepress.com/testimonials.php to read real quotes from published authors. 